\title{
Physical activity and colon cancer prevention: a meta-analysis
}

\author{
KY Wolin ${ }^{*, I}$, Y Yan', GA Colditz' and I-M Lee ${ }^{2,3}$ \\ 'Department of Surgery, Washington University School of Medicine, St Louis, MO, USA; '2Division of Preventive Medicine, Brigham and Women's Hospital \\ and Harvard Medical School, Boston, MA, USA; ${ }^{3}$ Department of Epidemiology, Harvard School of Public Health, Boston, MA, USA
}

\begin{abstract}
Although an inverse association between physical activity and risk of colon cancer is well established, a formal estimate of the magnitude of this risk reduction that includes recent studies is not available. This analysis examines the association by sex and study design, restricting analyses to studies where data for colon cancer alone were available. The authors reviewed published studies through June 2008 examining the association between physical activity and risk of colon cancer. Heterogeneity and publication bias were evaluated and random effects models used to estimate relative risks (RR). Differences by sex and study design were evaluated. A total of 52 studies were included. An inverse association between physical activity and colon cancer was found with an overall relative risk (RR) of 0.76 (95\% confidence interval $(\mathrm{Cl})$ : 0.72, $0.8 \mathrm{I}$ ). For men, the RR was 0.76 (95\% Cl: 0.7I, 0.82); for women, this was little different, $(R R=0.79,95 \% \mathrm{Cl}: 0.7 \mathrm{I}, 0.88)$. The findings from case-control studies were stronger $(\mathrm{RR}=0.69,95 \% \mathrm{Cl}: 0.65$, $0.74)$ than for cohort studies ( $R R=0.83,95 \% \mathrm{Cl}: 0.78,0.88)$. This study confirms previous studies reporting an inverse association between physical activity and colon cancer in both men and women, and provides quantitative estimates of the inverse association. British Journal of Cancer (2009) I 00, 6I I-616. doi: 10.1038/sj.bjc.66049 I7 www.bjcancer.com
\end{abstract}

Published online 10 February 2009

(c) 2009 Cancer Research UK

Keywords: physical activity; colon cancer; meta-analysis

Ample and consistent evidence exists for a significant, inverse association between physical activity and risk of developing colon cancer (International Agency for Research on Cancer WHO, 2002). Moreover, this association is plausibly supported by several biological mechanisms, including decreased inflammation, reduced intestinal transit time, decreased insulin-like growth factor levels, reduced hyperinsulinemia and modulated immune function with physical activity. Although several qualitative reviews of this literature have been conducted, an up-to-date meta-analysis of the studies of physical activity and colon cancer is not available (International Agency for Research on Cancer WHO, 2002; Slattery, 2004). One recent study quantitatively evaluated data on the relation between physical activity and risk of colon cancer, but also included colorectal cancer end points (Samad et al, 2005). No association has been consistently found for physical activity and rectal cancer, and the consensus is that one is unlikely to exist (International Agency for Research on Cancer WHO, 2002). Estimation of the risk reduction associated with physical activity separately for colon cancer is important for public health because the disease burden attributable to physical inactivity is likely underestimated by including rectal cancer end points. The World Health Organization conducted a meta-analysis using data from studies prior to 2000 , and estimated that $16 \%$ of the global colon cancer disease burden is due to physical inactivity (Bull et al, 2004). However, this meta-analysis was conducted several years ago, and also did not investigate differences by study design. Thus, we conducted a meta-analysis to estimate the

\footnotetext{
* Correspondence: Dr KY Wolin, Department of Surgery, Washington University School of Medicine, 660 S. Euclid Avenue, Box 8100 , St Louis, MO 63।I0, USA; E-mail: wolink@wustl.edu

Received 2 October 2008; revised 6 January 2009; accepted II January 2009; published online 10 February 2009
}

summary relative risk of colon cancer associated with physical activity, based on available studies to date.

\section{MATERIALS AND METHODS}

A search was conducted on PubMed for all publications in English through June 2008. The search terms physical activity, exercise, and colon cancer were used. In addition, previous reviews of the data (Slattery, 2004; Samad et al, 2005; Lee and Oguma, 2006) and the reference lists of included studies were reviewed.

We included only case-control or cohort studies with a colon cancer end point. Studies that reported the findings for rectal cancer or for colon and rectal cancers combined (colorectal cancer) were excluded for the reason detailed above. We did not limit studies by type of physical activity; thus, studies measuring total physical activity, recreational or leisure-time physical activity, physical activity in commuting and occupational physical activity could all be included.

From each article, the study design, sample size, age range, years of follow-up or type of control sample (depending on study design), type of physical activity and results were abstracted. We also abstracted the variables that each study used in its most adjusted analysis. We extracted information on study quality, including whether the study evaluated the accuracy of the physical activity instrument, whether physical activity was quantified, whether medical records were used to confirm the outcome or was a death certificate or tumour registry used to identify the outcome, and loss to follow-up or study response rate. Data extraction was performed by a single investigator (KYW).

An indicator of study quality was created where one point was assigned to studies for evaluation of physical activity instrument accuracy (i.e., instrument has been assessed for reliability or validity), and one point for quantification of physical activity 
(measured levels including that based on self report $v s$ qualitative description such as active vs inactive). All studies that reported on instrument accuracy found the instrument had fair reliability or validity. Studies that used medical records to evaluate the outcome received two points, whereas those that used a death certificate or tumour registry received one point. Studies that adjusted for age and some component of diet received one point; those that also adjusted for use of non-steroidal anti-inflammatory drugs or multivitamin use received an additional point. For cohort studies, those with loss to follow-up of less than $20 \%$ received one point. For case-control studies, those with a response rate over $70 \%$ for cases received 0.5 points, whereas those with a response rate of over $70 \%$ for controls received 0.5 points, for a total of 1 point. Thus, the maximum quality score was seven for both cohort and case-control studies. This indicator was based on one previously used by Oguma and Shinoda-Tagawa (2004).

\section{Data analysis}

Random effects meta-analysis was used to allow for the heterogeneity of results across studies. Data were processed in SAS and the analyses were performed using R-package 'meta'. We evaluated case-control and cohort studies separately, and also considered results for men and women separately when available. To evaluate the potential effects that increased screening might have, we conducted an exploratory analysis by time period. Finally, given the increasing interest in the effects of type of physical activity (Physical Activity Guidelines Advisory Committee, 2008), we conducted exploratory analysis separately for occupational and leisure-time physical activity for those studies where such data was available. In the main analyses, we did not adjust for study quality; in additional analyses to examine the impact of study quality, summary estimates across studies were adjusted for quality score. When multiple types of physical activity were reported we used a summary measure of total physical activity if provided in our main analysis. If multiple domain-specific physical activity results were reported, we included only the leisure-time physical activity in our primary analyses as this measure was available for most studies. When physical activity at different ages was recalled and assessed at a single time point, we used the age range that best represented adulthood (30-50 years old). As most studies reported relative risks (RR) or odds ratios (OR) and their associated $95 \%$ confidence intervals (CI), we used these data as summary statistics for each study. First, we derived the standard error of log (RR or OR) using the $95 \% \mathrm{CI}$, with the expression: [log (upper limit)-log (lower limit) $] / 2 \times 1.96$. These standard errors were used as weights for summary effect estimates in the meta-analysis. In quality score adjusted analysis, we combined quality score and the inverse of standard error for the weight based on the Shadish and Haddock formula, and used a modified 'metagen' function from the R-package 'meta' to implement the change (Shadish and Haddock, 1994). Given that many studies reported results separately for men and women, we included both estimates when reporting the overall association. In addition, we visually examined publication bias using Funnel plots and employed the rank correlation method to formally test for bias (Begg and Mazumdar, 1994).

\section{RESULTS}

We identified 507 potential studies. Of these we excluded those that were not conducted in humans $(n=5)$, review studies $(n=144)$, those whose outcome was not colon or colorectal cancer $(n=163)$, editorials/letters to the editor/comments $(n=8)$, those where physical activity was included only as a covariate and no data on the association with colon cancer was presented $(n=22)$, those with prevalence data only $(n=1)$, those where no physical activity data were presented $(n=4)$, those that reported data published elsewhere $(n=8)$, those with an English abstract but the body of the article was in a foreign language $(n=1)$, leaving 60 studies. We then excluded studies that did not present data for colon cancer separately (as opposed to colorectal cancer) leaving 54 studies. When data from the same study was reported in more than one article (i.e., updated reports over time using the same baseline data), we included only the most recent publication. One exception was the Harvard Alumni Health Study where physical activity from two different adult time periods (i.e., different baselines) was used in the two publications (Lee et al, 1991; Lee and Paffenbarger, 1994). Finally, we also excluded those studies that did not report a relative risk and 95\% confidence interval or crude data that allowed calculation of the relative risk and confidence interval $(n=2)$. This left a total of 52 studies, 24 case-control (Vena et al, 1985; Brownson et al, 1989; Fredriksson et al, 1989; Gerhardsson de Verdier et al, 1990; Kato et al, 1990; Slattery et al, 1990, 1997; Whittemore et al, 1990; Vetter et al, 1992; Arbman et al, 1993; Vineis et al, 1993; Marcus et al, 1994; Kotake et al, 1995; White et al, 1996; La Vecchia et al, 1999; Levi et al, 1999; Tang et al, 1999; Tavani et al, 1999; Juarranz et al, 2002; Yeh et al, 2003; Fernandez et al, 2004; Hou et al, 2004; Isomura et al, 2006; Zhang et al, 2006) and 28 cohort studies (Garabrant et al, 1984; Gerhardsson et al, 1986, 1988; Lynge and Thygesen, 1988; Severson et al, 1989; Brownson et al, 1991; Lee et al, 1991, 1997, 2007; Dosemeci et al, 1993; Fraser and Pearce, 1993; Bostick et al, 1994; Lee and Paffenbarger, 1994; Thune and Lund, 1996; Colbert et al, 2001; Chao et al, 2004; Wei et al, 2004; Schnohr et al, 2005; Calton et al, 2006; Friedenreich et al, 2006; Johnsen et al, 2006; Larsson et al, 2006; Mai et al, 2007; Takahashi et al, 2007; Wolin et al, 2007; Howard et al, 2008; Moradi et al, 2008; Nilsen et al, 2008), in the present analyses. We found significant heterogeneity in the estimates across studies $(P<0.0001)$ and thus employed random effects models. We found no statistical evidence of publication bias, using a funnel plot ( $P$ from rank correlation $=0.45$ ).

There was a significant $24 \%$ reduced risk of colon cancer when comparing the most $v s$ least active individuals across all studies $(\mathrm{RR}=0.76,95 \% \mathrm{CI}: 0.72,0.81)$. When we adjusted for quality score, the results held $(\mathrm{RR}=0.76,95 \% \mathrm{CI}$ : 0.74, 0.79).

Examining case-control and cohort studies separately, we found significant risk reductions for both study designs, with the magnitude being larger for case-control $(\mathrm{RR}=0.69,95 \%$ CI: $0.65,0.74)$, compared with cohort studies ( $R R=0.83,95 \%$ CI: $0.78,0.88)$ (Figure 1). When we examined men and women separately, we found similar results for both men $(\mathrm{RR}=0.76,95 \% \mathrm{CI} 0.71,0.82)$ and women $(\mathrm{RR}=0.79,95 \% \mathrm{CI}$ : $0.71,0.88)$. We further stratified the analyses by study design and gender, and observed generally similar results for men $(\mathrm{RR}=0.72,95 \% \mathrm{CI}: 0.66,0.79)$ and women $(\mathrm{RR}=0.68$, 95\% CI: $0.64,0.72$ ) in case-control studies. For the cohort studies, the risk reduction appeared larger in men $(\mathrm{RR}=0.81,95 \% \mathrm{CI}: 0.73,0.89)$, compared with women $(\mathrm{RR}=0.89,95 \% \mathrm{CI}: 0.81,0.99)$.

When examining differences over time, we found that the inverse association was not different between studies published before $1993(\mathrm{RR}=0.74,95 \% \mathrm{CI}: 0.67,0.82)$ and those published between 1993 and $1999(\mathrm{RR}=0.78,95 \% \mathrm{CI}$ : 0.70, 0.86) or after 1999 $(\mathrm{RR}=0.78,95 \% \mathrm{CI}: 0.73,0.83)$.

Of the 24 case-control studies, 17 provided data separately on occupational physical activity and 10 provided separate data on leisure-time physical activity. For the 28 cohort studies, these numbers were 15 and 16, respectively. The findings from analyses that considered these domain-specific physical activities mirrored those from the overall analyses. Occupational physical activity was associated with a significant risk reduction $(\mathrm{RR}=0.78,95 \%$ CI: $0.74,0.83$ ) for colon cancer. The effect was attenuated in cohort studies $(\mathrm{RR}=0.85,95 \% \mathrm{CI}: 0.77,0.93)$ as compared to case-control studies ( $R R=0.73,95 \%$ CI: $0.67,0.79)$. Similarly, leisure-time physical activity was associated with a similar risk reduction over all studies $(\mathrm{RR}=0.77,95 \% \mathrm{CI}: 0.72,0.82)$; the effect was attenuated in cohort ( $R R=0.82,95 \% \mathrm{CI}$ : $0.75,0.87)$, compared with case-control $(\mathrm{RR}=0.69,95 \% \mathrm{CI}: 0.62,0.78)$ studies. 
Studies with case-control study dedign
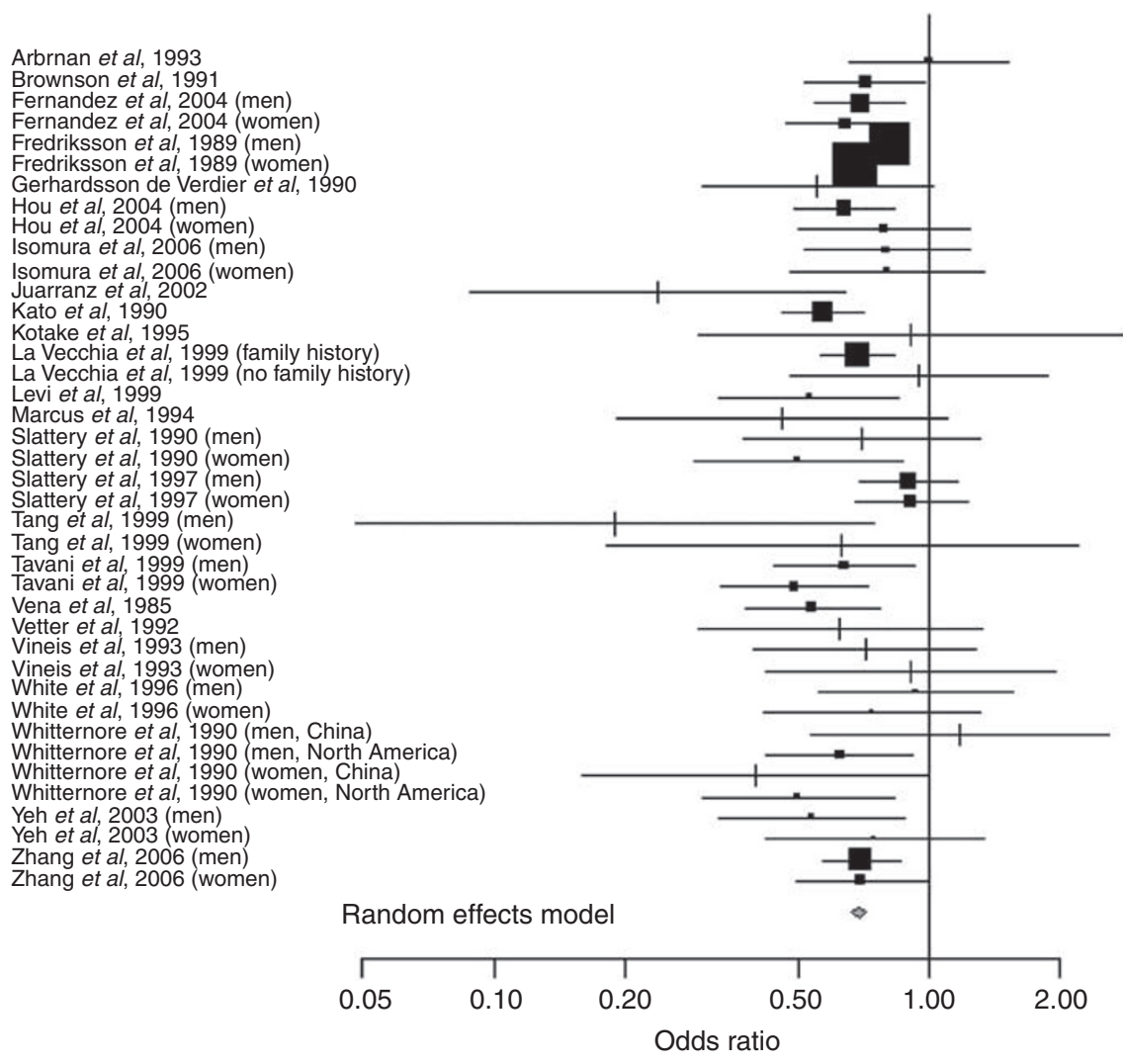

Figure I Meta-analysis of physical activity and colon cancer: case-control studies.

\section{DISCUSSION}

Previous reviews of the association between physical activity and colon cancer have reported a risk reduction of approximately $30 \%$, based on qualitative review, when comparing the most to the least active individuals (Lee and Oguma, 2006). Our formal metaanalysis of the data generally supports this, showing a $24 \%$ risk reduction overall, and generally similar risk reductions when men and women were examined separately. Several mechanisms have been proposed for the role of physical activity in reducing colon cancer risk including reduced insulin resistance and hyperinsulinemia, anti-inflammatory action, direct immune action, decreased intestinal transit time or higher vitamin D levels (Wolin et al, 2007). As future investigations explore these pathways, they will likely provide additional insights on the association between physical activity and colon cancer risk.

Although each study quantified activity differently limiting our ability to draw conclusions about the amount of physical activity necessary for the $24 \%$ risk reduction observed, a recent example provides some information. In the US Nurses' Health Study, Wolin et al (2007) report a $23 \%$ risk reduction when comparing the most to the least active women. The most active women expended more than 21.5 MET hours per week in leisure-time physical activity, whereas the least active expended less than 2 MET hours per week. These levels are equivalent to brisk walking for some 5-6h per week in the most active and $0.5 \mathrm{~h}$ per week in the least active.

We found that the magnitude of risk reduction reported in case-control studies were stronger than those reported in cohort studies (30 vs 15\% risk reduction), as also observed in a previous qualitative review (Lee and Oguma, 2006) and a previous metaanalysis (Samad et al, 2005). There are several possible reasons for this difference. Case-control studies may be subject to greater recall bias. Overall, we found no difference in risk reduction between men and women. This supports one previous qualitative review that found similar effects in women and men (Lee and Oguma, 2006), and contradicts suggestions that the beneficial effects of exercise may be attenuated in women (McTiernan $e t a l$, 2006; Mai et al, 2007). In their meta-analysis, Samad et al (2005) found a stronger association in men than women in cohort studies, but no difference in effects by gender in case-control studies . Similarly, we observed that cohort study results among women were less pronounced than those among men. This may be partly due to the small number of studies within each stratum. It may also reflect differences in the absolute physical activity values being compared, in that women typically report lower levels (intensity and duration) of physical activity than men, and higher levels of physical activity may be needed for risk reductions.

We found significant heterogeneity in the effects used in our analyses. This is not surprising given the variations in time of exposure assessment, length of follow-up, method of exposure assessment, type of physical activity assessed, levels of physical activity compared and covariates included in the analysis. To account for this heterogeneity, we used random effects models in our analyses.

Most cohort studies formally evaluated the presence of a doseresponse effect. Of the cohort studies, only four studies did not report a test of trend. Among the dose-response effects evaluated, less than half reported a significant trend. Of note, several studies that examined dose-response effects in men and women separately found significant trends only in men (Chao et al, 2004; Lee et al, 2007; Takahashi et al, 2007; Howard et al, 2008; Nilsen et al, 2008), but one found significant trends only in women (Thune and Lund, 1996) and two in both men and women (Wei et al, 2004; Moradi et $a l, 2008$ ). In contrast, only 10 case - control studies reported a test for trend, and four found significant results for at least one group. 

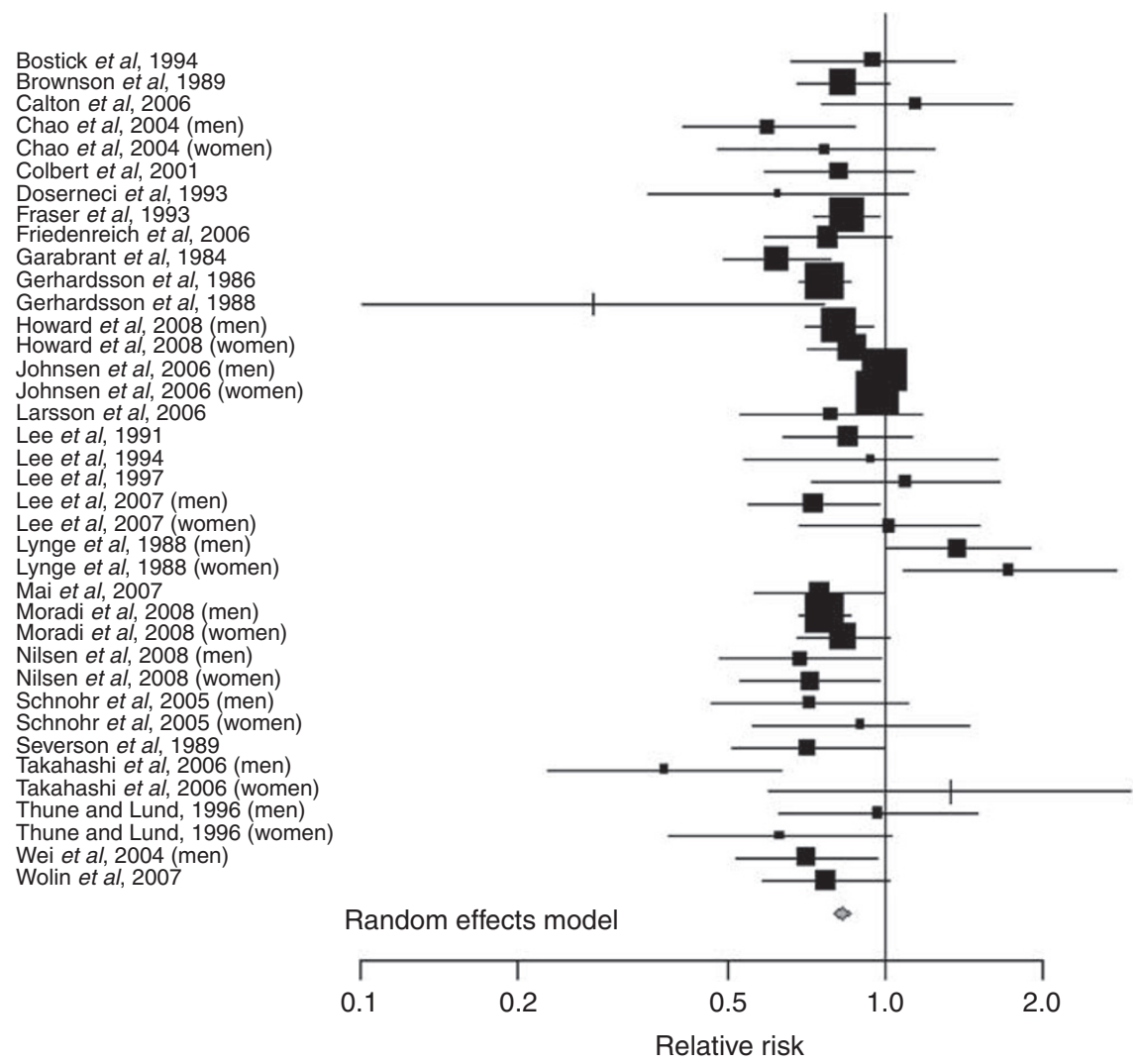

Figure 2 Meta-analysis of physical activity and colon cancer: cohort studies.

Because the studies used different physical activity measures in their tests for trend (e.g., energy expended, intensity, frequency, or duration), as well as different categorisation schemes, we did not conduct a formal meta-analysis of trend across studies (Figure 2).

Increasing interest has focused on the type, intensity or duration of physical activity necessary for a protective effect (Physical Activity Guidelines Advisory Committee, 2008). We were able to examine the effect of physical activity domain (occupational vs leisure-time) and found that the results were similar. Few studies have reported results in sufficient detail to allow a formal evaluation of the different effects of intensity or duration. Qualitative evaluations have suggested that vigorous physical activity may be necessary to reduce the risk (Slattery, 2004) though others have concluded that sufficient durations of moderate or vigorous intensity physical activity are likely to reduce the risk of colon cancer (Lee and Oguma, 2006). Recently, it has been suggested that walking alone may be sufficient to reduce risk (Takahashi et al, 2007; Wolin et al, 2007) though not all studies agree (Chao et al, 2004). Sufficient number of studies have not reported on the benefits of walking to allow formal evaluation of the effect. As additional studies report on the separate effects of intensity, duration and physical activity type, analyses of this data should be undertaken as these details are important to inform public health recommendations. Additional studies may also examine modification of the effect by race/ethnicity, BMI, diet and tumour location as the quantity of data on those factors increases.

We have previously hypothesised (Wolin et al, 2007) that the association between physical activity and colon cancer may be attenuating over time as screening decreases the number of colon tumours overall and distal colon tumours in particular. Fraser and Pearce (1993) examined secular trends in the association between occupational physical activity and risk of colon cancer and found that the association was stronger in the earlier era examined. However, this should be interpreted cautiously as other factors, including changes in the quality of physical activity assessment, may also contribute. In addition, the later studies also tended to adjust for larger numbers of potential confounders, typically attenuating relative risks. We found little evidence for a difference over time when we stratified the meta-analysis by publication year.

In conclusion, this meta-analysis provides additional support for the inverse association between physical activity and colon cancer. It provides a formal estimate showing that individuals can likely reduce their risk of colon cancer, overall, by $24 \%$ through participation in physical activity. Additional research on the type, intensity, and duration of physical activity that may afford the greatest risk reduction will inform public health recommendations regarding quantification of specific physical activity details.

\section{REFERENCES}

Arbman G, Axelson O, Fredriksson M, Nilsson E, Sjodahl R (1993) Do occupational factors influence the risk of colon and rectal cancer in different ways? Cancer 72: 2543-2549

Begg CB, Mazumdar M (1994) Operating characteristics of a rank correlation test for publication bias. Biometrics 50: 1088-1101
Bostick RM, Potter JD, Kushi LH, Sellers TA, Steinmetz KA, McKenzie DR, Gapstur SM, Folsom AR (1994) Sugar, meat, and fat intake, and non-dietary risk factors for colon cancer incidence in Iowa women (United States). Cancer Causes Control 5: $38-52$ 
Brownson RC, Chang JC, Davis JR, Smith CA (1991) Physical activity on the job and cancer in Missouri. Am J Public Health 81: 639-642

Brownson RC, Zahm SH, Chang JC, Blair A (1989) Occupational risk of colon cancer. An analysis by anatomic subsite. Am J Epidemiol 130: 675-687

Bull FC, Armstrong TP, Dixon T, Ham S, Neiman A, Pratt M (2004) Physical inactivity. In Comparative Quantification of Health Risks: Global and Regional Burden of Disease Attributable to Select Major Risk Factors Ezzati M, Lopez AD, Rodgers A, Murray CJL (eds), Vol. 1, World Health Organization: Geneva

Calton BA, Lacey Jr JV, Schatzkin A, Schairer C, Colbert LH, Albanes D, Leitzmann MF (2006) Physical activity and the risk of colon cancer among women: a prospective cohort study (United States). Int J Cancer 119: $385-391$

Chao A, Connell CJ, Jacobs EJ, McCullough ML, Patel AV, Calle EE, Cokkinides VE, Thun MJ (2004) Amount, type, and timing of recreational physical activity in relation to colon and rectal cancer in older adults: the Cancer Prevention Study II Nutrition Cohort. Cancer Epidemiol Biomarkers Prev 13: 2187-2195

Colbert LH, Hartman TJ, Malila N, Limburg PJ, Pietinen P, Virtamo J, Taylor PR, Albanes D (2001) Physical activity in relation to cancer of the colon and rectum in a cohort of male smokers. Cancer Epidemiol Biomarkers Prev 10: 265-268

Dosemeci M, Hayes RB, Vetter R, Hoover RN, Tucker M, Engin K, Unsal M, Blair A (1993) Occupational physical activity, socioeconomic status, and risks of 15 cancer sites in Turkey. Cancer Causes Control 4: 313-321

Fernandez E, Gallus S, La Vecchia C, Talamini R, Negri E, Franceschi S (2004) Family history and environmental risk factors for colon cancer. Cancer Epidemiol Biomarkers Prev 13: 658-661

Fraser G, Pearce N (1993) Occupational physical activity and risk of cancer of the colon and rectum in New Zealand males. Cancer Causes Control 4: $45-50$

Fredriksson M, Bengtsson NO, Hardell L, Axelson O (1989) Colon cancer, physical activity, and occupational exposures. A case-control study. Cancer 63: $1838-1842$

Friedenreich C, Norat T, Steindorf K, Boutron-Ruault MC, Pischon T, Mazuir M, Clavel-Chapelon F, Linseisen J, Boeing H, Bergman M, Johnsen NF, Tjonneland A, Overvad K, Mendez M, Quiros JR, Martinez C, Dorronsoro M, Navarro C, Gurrea AB, Bingham S, Khaw KT, Allen N, Key T, Trichopoulou A, Trichopoulos D, Orfanou N, Krogh V, Palli D, Tumino R, Panico S, Vineis $\mathrm{P}$, Bueno-de-Mesquita HB, Peeters $\mathrm{PH}$, Monninkhof E, Berglund G, Manjer J, Ferrari P, Slimani N, Kaaks R, Riboli E (2006) Physical activity and risk of colon and rectal cancers: the European prospective investigation into cancer and nutrition. Cancer Epidemiol Biomarkers Prev 15: 2398-2407

Garabrant DH, Peters JM, Mack TM, Bernstein L (1984) Job activity and colon cancer risk. Am J Epidemiol 119: 1005-1014

Gerhardsson M, Floderus B, Norell SE (1988) Physical activity and colon cancer risk. Int J Epidemiol 17: 743-746

Gerhardsson M, Norell SE, Kiviranta H, Pedersen NL, Ahlbom A (1986) Sedentary jobs and colon cancer. Am J Epidemiol 123: 775-780

Gerhardsson de Verdier M, Steineck G, Hagman U, Rieger A, Norell SE (1990) Physical activity and colon cancer: a case-referent study in Stockholm. Int J Cancer 46: 985-989

Hou L, Ji BT, Blair A, Dai Q, Gao YT, Chow WH (2004) Commuting physical activity and risk of colon cancer in Shanghai, China. Am J Epidemiol 160: 860 - 867

Howard RA, Freedman DM, Park Y, Hollenbeck A, Schatzkin A, Leitzmann MF (2008) Physical activity, sedentary behavior, and the risk of colon and rectal cancer in the NIH-AARP Diet and Health Study. Cancer Causes Control 19: 939-953

International Agency for Research on Cancer WHO (2002) IARC Handbooks of Cancer Prevention: Weight Control and Physical Activity, Vol. 6. International Agency for Research on Cancer: Lyon, France

Isomura K, Kono S, Moore MA, Toyomura K, Nagano J, Mizoue T, Mibu R, Tanaka M, Kakeji Y, Maehara Y, Okamura T, Ikejiri K, Futami K, Yasunami Y, Maekawa T, Takenaka K, Ichimiya H, Imaizumi N (2006) Physical activity and colorectal cancer: the Fukuoka Colorectal Cancer Study. Cancer Sci 97: 1099-1104

Johnsen NF, Christensen J, Thomsen BL, Olsen A, Loft S, Overvad K, Tjonneland A (2006) Physical activity and risk of colon cancer in a cohort of Danish middle-aged men and women. Eur J Epidemiol 21: $877-884$

Juarranz M, Calle-Puron ME, Gonzalez-Navarro A, Regidor-Poyatos E, Soriano T, Martinez-Hernandez D, Rojas VD, Guinee VF (2002) Physical exercise, use of Plantago ovata and aspirin, and reduced risk of colon cancer. Eur J Cancer Prev 11: $465-472$

Kato I, Tominaga S, Ikari A (1990) A case-control study of male colorectal cancer in Aichi Prefecture, Japan: with special reference to occupational activity level, drinking habits and family history. Jpn J Cancer Res 81: $115-121$

Kotake K, Koyama Y, Nasu J, Fukutomi T, Yamaguchi N (1995) Relation of family history of cancer and environmental factors to the risk of colorectal cancer: a case-control study. Jpn J Clin Oncol 25: 195-202

La Vecchia C, Gallus S, Talamini R, Decarli A, Negri E, Franceschi S (1999) Interaction between selected environmental factors and familial propensity for colon cancer. Eur J Cancer Prev 8: 147-150

Larsson SC, Rutegard J, Bergkvist L, Wolk A (2006) Physical activity, obesity, and risk of colon and rectal cancer in a cohort of Swedish men. Eur J Cancer 42: 2590-2597

Lee IM, Manson JE, Ajani U, Paffenbarger Jr RS, Hennekens CH, Buring JE (1997) Physical activity and risk of colon cancer: the Physicians' Health Study (United States). Cancer Causes Control 8: 568-574

Lee IM, Oguma Y (2006) Physical activity. In Cancer Epidemiology and Prevention, Schottenfeld D, Fraumeni Jr JF (eds), 3rd edn, pp 449-467. Oxford Univeristy Press: New York

Lee IM, Paffenbarger Jr RS (1994) Physical activity and its relation to cancer risk: a prospective study of college alumni. Med Sci Sports Exerc 26: $831-837$

Lee IM, Paffenbarger Jr RS, Hsieh C (1991) Physical activity and risk of developing colorectal cancer among college alumni. J Natl Cancer Inst 83: $1324-1329$

Lee KJ, Inoue M, Otani T, Iwasaki M, Sasazuki S, Tsugane S (2007) Physical activity and risk of colorectal cancer in Japanese men and women: the Japan Public Health Center-based prospective study. Cancer Causes Control 18: 199-209

Levi F, Pasche C, La Vecchia C, Lucchini F, Franceschi S (1999) Food groups and colorectal cancer risk. Br J Cancer 79: 1283-1287

Lynge E, Thygesen L (1988) Use of surveillance systems for occupational cancer: data from the Danish National system. Int J Epidemiol 17: $493-500$

Mai PL, Sullivan-Halley J, Ursin G, Stram DO, Deapen D, Villaluna D, Horn-Ross PL, Clarke CA, Reynolds P, Ross RK, West DW, Anton-Culver H, Ziogas A, Bernstein L (2007) Physical activity and colon cancer risk among women in the California Teachers Study. Cancer Epidemiol Biomarkers Prev 16: 517-525

Marcus PM, Newcomb PA, Storer BE (1994) Early adulthood physical activity and colon cancer risk among Wisconsin women. Cancer Epidemiol Biomarkers Prev 3: 641-644

McTiernan A, Yasui Y, Sorensen B, Irwin ML, Morgan A, Rudolph RE, Surawicz C, Lampe JW, Ayub K, Potter JD, Lampe PD (2006) Effect of a 12-month exercise intervention on patterns of cellular proliferation in colonic crypts: a randomized controlled trial. Cancer Epidemiol Biomarkers Prev 15: $1588-1597$

Moradi T, Gridley G, Bjork J, Dosemeci M, Ji BT, Berkel HJ, Lemeshow S (2008) Occupational physical activity and risk for cancer of the colon and rectum in Sweden among men and women by anatomic subsite. Eur J Cancer Prev 17: $201-208$

Nilsen TI, Romundstad PR, Petersen H, Gunnell D, Vatten LJ (2008) Recreational physical activity and cancer risk in subsites of the colon (the Nord-Trondelag Health Study). Cancer Epidemiol Biomarkers Prev 17: $183-188$

Oguma Y, Shinoda-Tagawa T (2004) Physical activity decreases cardiovascular disease risk in women: review and meta-analysis. Am J Prev Med 26: $407-418$

Physical Activity Guidelines Advisory Committee (2008) Physical Activity Guidelines Advisory Committee Report, 2008. Department of Health and Human Services: Washington, DC, USA

Samad AK, Taylor RS, Marshall T, Chapman MA (2005) A meta-analysis of the association of physical activity with reduced risk of colorectal cancer. Colorectal Dis 7: 204-213

Schnohr P, Gronbaek M, Petersen L, Hein HO, Sorensen TI (2005) Physical activity in leisure-time and risk of cancer: 14-year follow-up of 28000 Danish men and women. Scand J Public Health 33: 244-249

Severson RK, Nomura AM, Grove JS, Stemmermann GN (1989) A prospective analysis of physical activity and cancer. Am J Epidemiol 130: $522-529$

Shadish WR, Haddock CK (1994) Combining estimates of effect size. In The Handbook of Research Synthesis Cooper H, Hedges L (eds). Russell Sage Foundation: Newbury Park, CA 
Slattery ML (2004) Physical activity and colorectal cancer. Sports Med 34: $239-252$

Slattery ML, Abd-Elghany N, Kerber R, Schumacher MC (1990) Physical activity and colon cancer: a comparison of various indicators of physical activity to evaluate the association. Epidemiology 1: $481-485$

Slattery ML, Edwards SL, Ma KN, Friedman GD, Potter JD (1997) Physical activity and colon cancer: a public health perspective. Ann Epidemiol 7: $137-145$

Takahashi H, Kuriyama S, Tsubono Y, Nakaya N, Fujita K, Nishino Y, Shibuya D, Tsuji I (2007) Time spent walking and risk of colorectal cancer in Japan: the Miyagi Cohort study. Eur J Cancer Prev 16: 403-408

Tang R, Wang JY, Lo SK, Hsieh LL (1999) Physical activity, water intake and risk of colorectal cancer in Taiwan: a hospital-based case-control study. Int J Cancer 82: 484-489

Tavani A, Braga C, La Vecchia C, Conti E, Filiberti R, Montella M, Amadori D, Russo A, Franceschi S (1999) Physical activity and risk of cancers of the colon and rectum: an Italian case-control study. Br J Cancer 79: $1912-1916$

Thune I, Lund E (1996) Physical activity and risk of colorectal cancer in men and women. Br J Cancer 73: 1134-1140

Vena JE, Graham S, Zielezny M, Swanson MK, Barnes RE, Nolan J (1985) Lifetime occupational exercise and colon cancer. Am J Epidemiol 122: $357-365$
Vetter R, Dosemeci M, Blair A, Wacholder S, Unsal M, Engin K, Fraumeni Jr JF (1992) Occupational physical activity and colon cancer risk in Turkey. Eur J Epidemiol 8: 845-850

Vineis P, Ciccone G, Magnino A (1993) Asbestos exposure, physical activity and colon cancer: a case-control study. Tumori 79: 301-303

Wei EK, Giovannucci E, Wu K, Rosner B, Fuchs CS, Willett WC, Colditz GA (2004) Comparison of risk factors for colon and rectal cancer. Int J Cancer 108: $433-442$

White E, Jacobs EJ, Daling JR (1996) Physical activity in relation to colon cancer in middle-aged men and women. Am J Epidemiol 144: $42-50$

Whittemore AS, Wu-Williams AH, Lee M, Shu Z, Gallagher RP, Deng-ao J, Lun Z, Xianghui W, Kun C, Jung D, Teh CZ, Chengde L, Yao XJ, Paffenbarger RS, Henderson BE (1990) Diet, physical activity, and colorectal cancer among Chinese in North America and China. J Natl Cancer Inst 82: 915-926

Wolin KY, Lee IM, Colditz GA, Glynn RJ, Fuchs C, Giovannucci E (2007) Leisure-time physical activity patterns and risk of colon cancer in women. Int J Cancer 121: 2776-2781

Yeh CC, Hsieh LL, Tang R, Chang-Chieh CR, Sung FC (2003) Risk factors for colorectal cancer in Taiwan: a hospital-based case-control study. J Formos Med Assoc 102: 305-312

Zhang Y, Cantor KP, Dosemeci M, Lynch CF, Zhu Y, Zheng T (2006) Occupational and leisure-time physical activity and risk of colon cancer by subsite. J Occup Environ Med 48: 236-243 